\title{
Aromathérapie contre les animalcules
}

Si nous vivons plus ou moins en harmonie avec une multitude de bactéries dans nos voies digestives, et que nous abritons

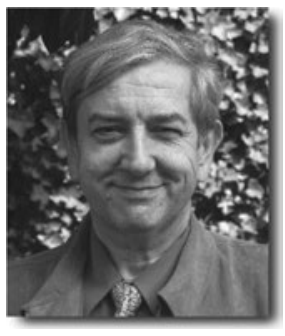
souvent en nous des parasites en dormance, nous ne sommes pas aptes à coexister avec d'autres animalcules.

En Occident nous avons à nous battre avec les tiques et l'échinocoque, en Afrique avec les filaires et la bilharziose, en Orient avec la dengue et autres.

Alors que nous en avons à peine fini avec le paludisme en Europe méridionale, en partie grâce à l'eucalyptus, la lutte avec des ectoparasitoses ne fait que commencer : poux, puces, gale, tiques, moustiques de tous genres...

À la place de l'Aedes aegypti, porteur de malaria, la France métropolitaine fait maintenant face au chikungunya (liée à un arbovirus) par l'intermédiraire de A. aegypti et $A$. albopictus. La fièvre volhynienne, ou fièvre des tranchées, due à une rickettsie ( Bartonella quitana»), qui a fait des ravages sur le front germano-

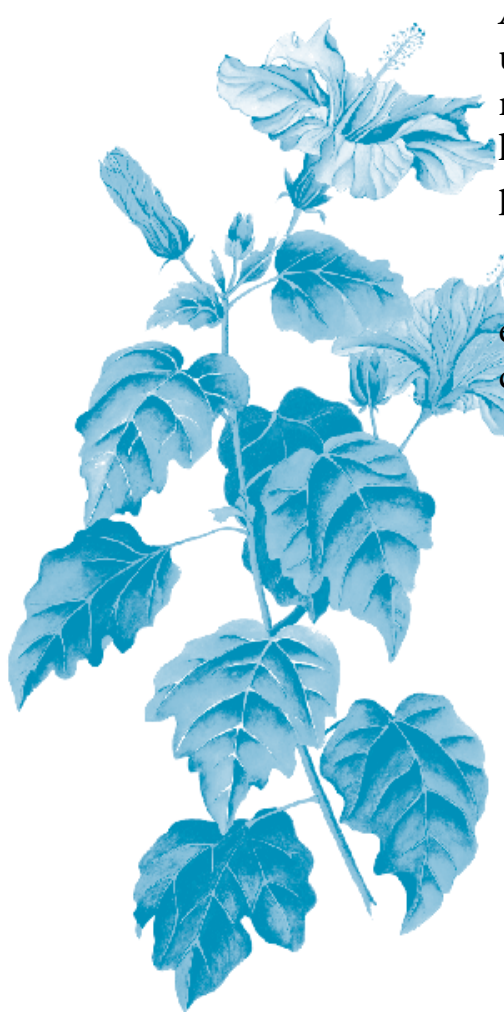

P. Goetz

Rédacteur en chef Enseignant de phytothérapie clinique au D.U. de phytothérapie de la faculté de médecine Paris-XIII 